\title{
KEPATUHAN PERAWAT DALAM PENERAPAN LIMA BENAR PEMBERIAN OBAT
}

\section{NURSING COMPLIANCE IN THE IMPLEMENTATION OF THE FIVE RIGHT OF DRUGS ADMINISTRATION}

\author{
Kevin Imanuel Cessar Diongano ${ }^{1 *}$, Ruben Hutagalung ${ }^{2}$, Wulan Ayu Revina ${ }^{3}$, \\ Marisa Junianti Manik ${ }^{4^{*}}$, Elfrida Silalahi ${ }^{5}$ \\ 1,2,3,4,5Fakultas Keperawatan Universitas Pelita Harapan \\ E-mail: ${ }^{1}$ kevincessar11@gmail.com, ${ }^{2}$ ruben.hutagalung16@gmail.com, ${ }^{3}$ wulanarm@gmail.com \\ 4*marisa.manik@uph.edu ${ }^{5}$ elfrida.silalahi@uph.edu
}

\begin{abstract}
ABSTRAK
Perawat merupakan tenaga kesehatan yang memegang peranan penting dalam keamanan pasien terutama pada pemberian obat. Terdapat prinsip benar pemberian obat yang harus diterapkan untuk mencegah kesalahan dalam pemberian obat. Kepatuhan perawat sangat diperlukan dalam menerapkan prinsip pemberian obat sesuai dengan Standar Prosedur Operasional rumah sakit untuk menjamin keselamatan pasien. Penelitian ini bertujuan untuk mengetahui gambaran kepatuhan perawat dalam penerapan lima benar pemberian obat di ruang rawat inap di satu rumah sakit swasta di Indonesia Tengah. Penelitian ini menggunakan metode deskriptif kuantitatif. Populasi penelitian ini adalah seluruh perawat di ruang rawat inap. Sampel sebanyak 17 orang dipilih menggunakan teknik total sampling. Instrumen yang digunakan adalah lembar checklist observasi dan teknik analisis data menggunakan analisis univariat dan penelitian ini dilakukan selama bulan Juni 2019. Hasil penelitian menunjukkan 12 perawat tidak patuh $(70,59 \%)$ dalam penerapan prinsip lima benar pemberian obat. Benar pasien terdapat 12 perawat tidak patuh (70,59\%). Benar obat terdapat 17 perawat patuh $(100 \%)$. Benar dosis terdapat sembilan perawat $(52,95 \%)$ tidak patuh. Benar waktu terdapat 10 perawat patuh (58,82\%). Benar cara pemberian terdapat 16 perawat patuh $(94,11 \%)$. Bagi peneliti selanjutnya, disarankan untuk mencari faktor-faktor yang memengaruhi kepatuhan perawat dalam penerapan prinsip benar pemberian obat.
\end{abstract}

\section{Kata Kunci : Kepatuhan, Perawat, Prinsip lima benar, Pemberian obat}

\begin{abstract}
Nurses are health workers that play an important role in patient safety, especially in drug administration. In administering medication there are principles of right medication administration that must be applied to prevent errors in drug administration. Nurse's compliance is very necessary for applying the principle of drug administration according to the Hospital's Standards Operating Procedure to ensure patient safety. This research aims to describe a descriptive study of nurse compliance in implementing the five rights of medication administering in inpatient rooms of a private hospital in central Indonesia. This study uses the descriptive quantitative method. The population in this study was nurses in the inpatient room. The total sample of 17 people was selected using the total sampling technique. The instrument used is the observation checklist sheet while the data analysis technique used in the univariate analysis and the research was conducted in June 2019. The results of the study showed five nurses 12 nurses who were not obedient (70.59\%) in applying the five rights principles of drug administration. The right patient had 12 nurses who were not obedient $(70.59 \%)$. Right medication, there are 17 nurses who obey (100\%). Right dosage there were nine nurses $(52.95 \%)$ who did not obey. Right time there were 10 nurses who were obedient $(58.82 \%)$. The right route had 16 nurses who were obedient (94.11\%). For future research, it is recommended
\end{abstract}


to look for factors that influence nurse compliance in applying the correct principle of drug administration.

Keywords: Compliance, Five rights, Medication administration, Nurses

\section{PENDAHULUAN}

Rumah sakit adalah institusi pelayanan kesehatan bagi masyarakat untuk meningkatkan pelayanan bermutu dan terjangkau agar terwujud derajat kesehatan yang setinggi-tingginya. Rumah sakit juga berperan penting dalam menjamin keselamatan pasien dengan memberikan pelayanan sesuai dengan standar yang ditetapkan. Kepatuhan perawat sebagai tenaga kesehatan sangat diperlukan dalam menerapkan prosedur keselamatan pasien ${ }^{1}$. Perawat memegang peranan penting dalam keamanan klien, terutama pada persiapan dan pemberian obat, dan mengajarkan cara menggunakan obat serta mengevaluasi respon pasien².

Ada enam prinsip benar dalam pemberian obat yaitu benar obat, benar dosis, benar pasien, benar jalur, benar waktu, dan benar dokumentasi ${ }^{2}$. Standar Prosedur Operasional (SPO) pemberian obat tempat peneliti meneliti menggunakan prinsip lima benar yaitu benar pasien, benar obat, benar dosis, benar waktu, dan benar cara pemberian. Kesalahan dalam pemberian obat dapat dicegah dengan menerapkan prinsip benar pemberian obat berdasarkan standar yang berlaku. Apabila tidak diterapkan dengan teliti bisa menimbulkan kerugian baik bagi rumah sakit, perawat, maupun keselamatan pasien seperti bisa mengakibatkan cedera bahkan bisa menyebabkan kematian.

Kesalahan dalam pemberian obat terjadi pada satu dari 10 pasien di dunia. Jenis kesalahan yang menyebabkan kematian meliputi $40,9 \%$ salah dosis, $16 \%$ salah obat dan $9,5 \%$ salah dalam rute pemberian $^{3}$. Kesalahan dalam pemberian obat menjadi penyebab penting terhadap morbiditas dan mortalitas pasien dan dapat berdampak kepada pasien, keluarga, maupun penyedia layanan kesehatan ${ }^{4}$.
Menurut laporan dari Institute of Medicine kesalahan medis di Amerika Serikat mengakibatkan 44.000 hingga 98.000 pasien meninggal setiap tahun dan sebagian dari kejadian ini terkait dengan kesalahan pemberian obat ${ }^{4}$. Untuk Indonesia sendiri untuk kesalahan dalam pemberian obat belum terdata secara sistematis dan sistem pelaporan yang terdokumentasi masih belum banyak dilaksanakan ${ }^{3}$. RSUD dr. Zainoel Abidin Banda Aceh tahun 2015 mendapatkan data terdapat kejadian 20 insiden, enam laporan di antaranya merupakan kesalahan dalam pemberian obat ${ }^{5}$. Fatimah (2016) dalam penelitiannya kepada 32 perawat mengenai penerapan prinsip dalam pemberian obat di ruang rawat inap sebuah rumah sakit di Yogyakarta, terdapat paling banyak dalam kategori cukup yaitu 59,4\% ${ }^{6}$.

Data laporan kejadian di tempat peneliti melakukan penelitian selama bulan Oktober 2018 - Februari 2019 terdapat delapan kejadian terkait dengan ketidaksesuaian pengobatan oleh perawat diantaranya ketidaksesuaian dosis, waktu pemberian, serta salah pemberian obat kepada pasien. Hasil observasi peneliti selama Desember 2018 - Januari 2019 ditemukan bahwa dalam satu kali shift satu orang perawat merawat delapan sampai sepuluh pasien. Peneliti juga menemukan lima perawat belum menerapkan prinsip lima benar dalam pemberian obat dengan baik sesuai dengan SPO yang berlaku, seperti tidak mengecek identitas pasien, dan tidak mengecek kembali Inpatient Medical Report (IMR) sebelum pemberian obat, ketidaksesuian waktu pemberian obat, ketidaksesuaian dosis, dan ketidaksesuaian obat pada seorang pasien, sehingga pasien harus mendapat observasi khusus. Kejadian ini dapat terus bertambah apabila tidak ada perhatian dari 
perawat untuk melakukan setiap prinsip benar dalam pemberian obat.

Berdasarkan fenomena yang dijelaskan, penelitian ini bertujuan untuk mendapatkan gambaran kepatuhan perawat dalam penerapan lima benar pemberian obat di ruang rawat inap di salah satu rumah sakit swasta di Indonesia tengah.

\section{METODE}

Penelitian ini menggunakan desain deskriptif kuantitatif. Populasi penelitian ini adalah seluruh perawat di ruang rawat inap di satu rumah sakit swasta di Indonesia tengah. Sampel penelitian ini berjumlah 17 orang dipilih dengan teknik total sampling. Instrumen penelitian ini berupa lembar checklist observasi berdasarkan SPO yang berlaku. Instrumen ini menggunakan skala nominal dengan dua penilaian yaitu dilakukan atau tidak dilakukan.

Pengambilan data dilakukan selama bulan Juni 2019. Sebelum melakukan penelitian, dilakukan uji Cohens Kappa untuk melihat tingkat kesepahaman antar observer. Pemberian informed consent dan penjelasan mengenai penelitian juga dilakukan kepada responden. Observasi dilakukan sewaktu perawat melakukan pemberian obat pada tiga pasien yang berbeda dan melihat konsistensi yang dilakukan. Apabila perawat tidak melakukan salah satu atau lebih dari item yang ada, maka perawat dinilai tidak patuh dalam menerapkan prinsip lima benar pemberian obat.

\section{HASIL}

Hasil penelitian menunjukkan sebagian besar perawat 12 perawat $(70,59 \%)$ tidak patuh dalam menerapkan seluruh prinsip lima benar pemberian obat sesuai dengan SPO.
Tabel 1. Distribusi kepatuhan perawat dalam penerapan prinsip benar pasien

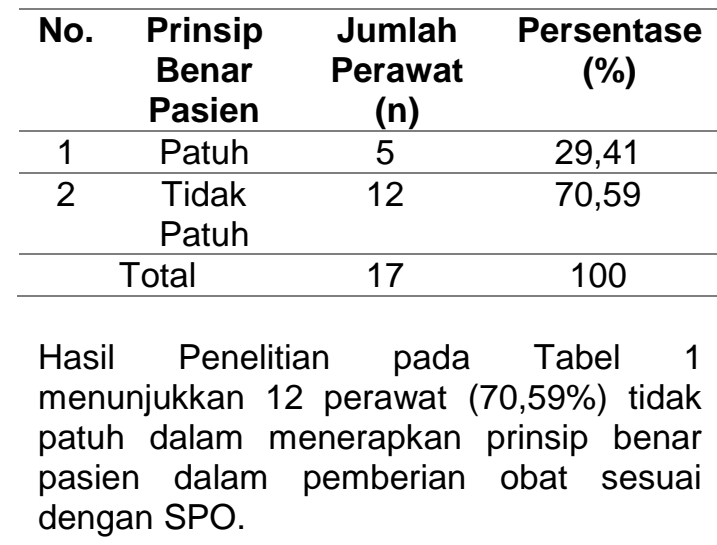

Tabel 2. Distribusi kepatuhan perawat dalam penerapan prinsip benar obat

\begin{tabular}{cccc}
\hline No. & $\begin{array}{c}\text { Prinsip } \\
\text { Benar } \\
\text { Obat }\end{array}$ & $\begin{array}{c}\text { Jumlah } \\
\text { Perawat } \\
(\mathbf{n})\end{array}$ & $\begin{array}{c}\text { Persentase } \\
\text { (\%) }\end{array}$ \\
\hline 1 & Patuh & 17 & 100 \\
\hline 2 & $\begin{array}{c}\text { Tidak } \\
\text { Patuh }\end{array}$ & 0 & 0 \\
\hline & Total & 17 & 100 \\
\hline
\end{tabular}

Hasil penelitian pada Tabel 2 menunjukkan semua perawat (100\%) patuh dalam menerapkan prinsip benar obat dalam pemberian obat sesuai dengan SPO.

Tabel 3. Distribusi kepatuhan perawat dalam penerapan prinsip benar dosis

\begin{tabular}{cccc} 
No. & $\begin{array}{c}\text { Prinsip } \\
\text { Benar } \\
\text { Dosis }\end{array}$ & $\begin{array}{c}\text { Jumlah } \\
\text { Perawat } \\
(\mathbf{n})\end{array}$ & $\begin{array}{c}\text { Persentase } \\
\text { (\%) }\end{array}$ \\
\hline 1 & Patuh & 8 & 47,05 \\
\hline 2 & $\begin{array}{c}\text { Tidak } \\
\text { Patuh }\end{array}$ & 9 & 52,95 \\
\hline & Total & 17 & 100 \\
\hline
\end{tabular}

Hasil penelitian pada Tabel 3 dapat dilihat masih banyak perawat tidak patuh dalam melakukan seluruh prinsip benar dosis dalam pemberian obat sesuai dengan Standar Prosedur Operasional yang berlaku yaitu sembilan perawat $(52,95 \%)$. 
Tabel 4. Distribusi kepatuhan perawat dalam penerapan prinsip benar waktu

\begin{tabular}{cccc}
\hline No. & $\begin{array}{c}\text { Prinsip } \\
\text { Benar } \\
\text { Waktu }\end{array}$ & $\begin{array}{c}\text { Jumlah } \\
\text { Perawat } \\
\text { (n) }\end{array}$ & $\begin{array}{c}\text { Persentase } \\
\text { (\%) }\end{array}$ \\
\hline 1 & Patuh & 10 & 58,82 \\
\hline 2 & $\begin{array}{c}\text { Tidak } \\
\text { Patuh }\end{array}$ & 7 & 41,48 \\
& Total & 17 & 100 \\
\hline
\end{tabular}

Berdasarkan Tabel 4 dapat diketahui bahwa sebagian besar perawat patuh dalam menerapkan prinsip benar waktu dalam pemberian obat sesuai dengan SPO yaitu sebanyak 10 perawat $(58,82 \%)$.

Tabel 5. Distribusi kepatuhan perawat dalam penerapan prinsip benar cara pemberian

\begin{tabular}{cccc}
\hline No. & $\begin{array}{c}\text { Prinsip } \\
\text { Benar } \\
\text { Cara } \\
\text { Pemberi- } \\
\text { an }\end{array}$ & $\begin{array}{c}\text { Jumlah } \\
\text { Perawat } \\
\text { (n) }\end{array}$ & $\begin{array}{c}\text { Persentase } \\
(\%)\end{array}$ \\
\hline 1 & Patuh & 16 & 94,11 \\
\hline 2 & $\begin{array}{l}\text { Tidak } \\
\text { Patuh }\end{array}$ & 1 & 5,89 \\
\hline & Total & 17 & 100 \\
\hline
\end{tabular}

Berdasarkan Tabel 5 dapat diketahui 16 perawat patuh $(94,11 \%)$ dalam menerapkan prinsip benar cara pemberian dalam pemberian obat sesuai dengan SPO yang berlaku.

\section{PEMBAHASAN}

Prinsip Lima Benar Pemberian Obat. Perawat yang tidak patuh dalam hasil penelitian ini bukan berarti melakukan kesalahan dalam pemberian obat, namun setiap prinsip lima benar pemberian obat terdapat beberapa item yang harus dilakukan. Apabila salah satu item atau lebih tidak dilakukan maka perawat tersebut dikatakan tidak patuh atau belum menerapkan SPO pemberian obat sesuai yang berlaku.

Hasil penelitian ini sejalan dengan penelitian Fatimah (2016) yang menunjukkan bahwa perawat dalam menerapkan prinsip enam benar paling banyak kategori cukup yaitu $59,4 \%{ }^{6}$. Hasil ini berbeda dengan penelitian Mahfudah dan Melani (2018) yang menunjukkan $92,5 \%$ perawat berada dalam kategori baik?

Berdasarkan hasil observasi peneliti mendapati satu perawat merawat delapan sampai sepuluh pasien dalam satu shift. Rumah sakit tempat penelitian dilakukan merupakan rumah sakit tipe C. Berdasarkan Peraturan Menteri Kesehatan RI No.340/MENKES/PER/III/2010 tentang klasifikasi rumah sakit, disampaikan bahwa perbandingan jumlah tempat tidur dengan jumlah perawat untuk rumah sakit tipe $C$ adalah dua perawat berbanding tiga tempat tidur. Jumlah perawat dan jumlah pasien yang tidak sebanding dapat menambah beban kerja sehingga dapat memengaruhi kepatuhan perawat dalam penerapan lima benar pemberian obat.

Menurut Gorgich, Barfroshan, Ghoreishi, dan Yaghoobi (2015) salah satu faktor penting yang dapat menimbulkan kesalahan dalam pemberian obat yaitu kelelahan karena beban kerja yang tinggi ${ }^{8}$. Hosseinzadeh, Aghajari, dan Mahdavi (2012) juga mengatakan penyebab paling penting kesalahan dalam pengobatan adalah kekurangan staf dan kelelahan karena beban kerja yang tinggi ${ }^{9}$. Ketidakpatuhan perawat akan berdampak bagi pelayanan di rumah sakit, pasien, dan tenaga kesehatan jika terus dibiarkan tanpa adanya pengawasan dan pencegahan.

Menurut Indarti, Aulawi, dan Kristanti (2009) dampak yang bisa ditimbulkan apabila prinsip benar dalam pemberian obat tidak dilakukan dengan benar yaitu dapat merugikan pasien dan jika terus dibiarkan bisa saja menimbulkan kesalahan pengobatan yang bisa berakibat buruk dan merugikan bagi pasien, akibat terburuk yang dapat terjadi yaitu cedera serius juga kematian ${ }^{10}$. Mahajan (2011) menyebutkan kesalahan pengobatan masih menjadi penyebab penting 
morbiditas dan mortalitas pasien ${ }^{4}$. Menurut laporan dari Institute of Medicine kesalahan medis di Amerika Serikat mengakibatkan 44.000 hingga 98.000 pasien meninggal setiap tahun dan sebagian dari kejadian ini terkait dengan kesalahan pemberian obat ${ }^{4}$.

Dalam penelitiannya Indarti, Aulawi, dan Kristanti (2009) menyebutkan dampak bagi rumah sakit ketika terjadi kesalahan pada pemberian obat oleh tenaga kesehatan yaitu dapat mencerminkan belum maksimalnya pelayanan yang diberikan sehingga dapat membuat kepercayaan pengguna layanan kesehatan juga menurun ${ }^{10}$. Mahajan (2011) juga menyatakan bahwa konsekuensi terjadinya kesalahan pengobatan dapat berdampak menurunnya kepercayaan pasien, keluarga, dan publik ${ }^{4}$.

Perawat, dokter dan tenaga kesehatan lainnya dapat mendapat tuntutan hukum dan berujung pada sanksi berupa sanksi administratif maupun pidana ketika melakukan kesalahan dalam pemberian obat yang berkibat fatal bagi pasien. Berdasarkan Undang-Undang No. 36 Tahun 2014 tentang tenaga kesehatan pasal 77 mengenai penyelesaian perselisihan yaitu setiap penerima pelayanan kesehatan yang dirugikan akibat kesalahan atau kelalaian tenaga kesehatan dapat meminta ganti rugi sesuai dengan ketentuan peraturan perundangundangan. Pada pasal 84 dijelaskan bahwa sanksi yang diberikan antara lain ketika melakukan kelalaian berat yang mengakibatkan penerima pelayanan kesehatan luka berat dapat pidana penjara selama tiga tahun, apabila mengakibatkan kematian dapat pidana penjara selama tiga tahun.

Disiplin perawat sangat dibutuhkan dalam menjalankan prinsip benar dalam pemberian obat karena merupakan salah satu kunci keberhasilan dalam pelaksanaan pemberian obat. Hasil penelitian menunjukkan bahwa kepatuhan perawat dalam penerapan prinsip lima benar pemberian obat di ruang rawat inap di satu rumah sakit swasta di Indonesia tengah masih kurang.

\section{Prinsip Benar Pasien.}

Hasil penelitian ini menunjukkan bahwa $70,59 \%$ perawat di ruang rawat inap belum menerapkan seluruh item dalam prinsip benar pasien sesuai dengan SPO yang berlaku. Item terbanyak yang tidak dilakukan yaitu memeriksa nama pasien, nomor rekam medis/ tanggal lahir pada IMR, mencocokkan dengan gelang nama pasien.

Hasil penelitian ini sejalan dengan penelitian Solagracia (2017) di mana hasil penelitiannya menunjukkan $97 \%$ perawat tidak mencocokkan identitas pasien minimal dengan dua identitas, dan terdapat $87,2 \%$ tidak mencocokkan identitas pada gelang nama pasien ${ }^{11}$. Hasil yang berbeda dengan penelitian Dewi (2017), perawat yang menerapkan prinsip benar pasien sebanyak $80,65 \%{ }^{12}$. Berdasarkan hasil observasi ketika melakukan pemberian obat sebagian besar perawat hanya langsung memberikan obat dan menjelaskan jenis obat yang akan diminum tanpa menanyakan dan memeriksa identitas pasien.

Prinsip benar pasien adalah langkah dasar dalam memberikan obat dengan aman. Prinsip ini sangat menentukan dalam prinsip pemberian obat. Jika terjadi kesalahan dalam penerapan prinsip benar pasien, maka bisa menimbulkan kerugian bagi pasien dan juga pada tenaga kesehatan (Solagracia, 2017) ${ }^{11}$. Prinsip benar pasien merupakan langkah penting dalam pemberian obat dengan meyakinkan bahwa obat akan diberikan pada pasien yang benar ${ }^{13}$. Menurut Eldarjali (2011) untuk mengidentifikasi seorang pasien diperlukan dua cara yaitu, mengecek nama pasien, nomor rekam medis, tanggal lahir dan gelang pasien ${ }^{14}$. Dampak yang bisa saja terjadi apabila tidak dilakukan pemeriksaan identitas pasien yaitu ketidaksesuaian pasien sehingga bisa menimbulkan hal yang tidak diharapkan dalam pemberian obat. 


\section{Prinsip Benar Obat.}

Hasil penelitian menunjukkan sebagian besar perawat di ruang rawat inap sudah menerapkan seluruh item prinsip benar obat sesuai dengan SPO yang ditetapkan. Hasil penelitian ini sejalan penelitian Pranasari (2016) yang menunjukkan penerapan prinsip benar obat dengan kriteria baik sebanyak $87,8 \%{ }^{3}$. Hasil observasi dalam penelitian ini menunjukkan perawat sudah melakukan prosedur sesuai dengan SPO yang berlaku saat mempersiapkan obat sebelum diberikan kepada pasien. Hasil penelitian ini sejalan dengan penelitian Sthephani, Dewanto, Widijati (2015) yang menunjukkan bahwa $86,5 \%$ perawat melakukan prinsip benar obat dengan baik ${ }^{15}$.

Salah satu tugas terpenting perawat yaitu memberikan obat yang aman dan akurat kepada pasien. Obat merupakan terapi yang digunakan dokter untuk mengobati pasien yang memiliki masalah kesehatan. Meskipun obat memiliki manfaat dalam beberapa hal, namun beberapa obat dapat berpotensi menimbulkan efek yang bisa membahayakan kepada pasien apabila tidak diberikan dengan tepat. Perawat bertanggung jawab memahami kerja obat dan efek samping yang ditimbulkan, memberikan obat dengan tepat, memantau respon pasien dan membantu pasien menggunakannya dengan benar².

\section{Prinsip Benar Dosis.}

Hasil penelitian ini menunjukkan sebagian besar perawat tidak patuh dalam menerapkan seluruh item dalam prinsip benar dosis. Tindakan yang banyak tidak dilakukan yaitu perawat melakukan double-check bersama perawat lainnya sebelum memberikan obat. Ketika mempersiapkan obat beberapa perawat hanya mempersiapkan obatnya sendiri dan beberapa perawat tidak melakukan double-check dikarenakan perawat tersebut hanya dinas sendirian.

Hasil penelitian ini sejalan dengan penelitian Solagracia (2017) yang menunjukkan $92,3 \%$ perawat tidak melakukan double-check obat dan hasil hitungan dosis bersama perawat lain ${ }^{11}$. Hasil berbeda didapatkan dari penelitian Mahfudah dan Melani (2018) yang menunjukkan bahwa seluruh responden yang berjumlah 67 orang melakukan prinsip benar dosis dengan baik ${ }^{7}$. Menurut Tirtawati (2014) prinsip benar dosis bisa mengurangi kesalahan dalam pemberian obat $^{16}$. Perawat sangat perlu mengecek kembali obat dan dosis yang akan diberikan jika ada penulisan obat atau dosis yang kurang jelas.

Benar dosis merupakan salah satu tolak ukur keberhasilan peran perawat sebagai seorang kolaborator. Ketepatan dosis obat dapat mempercepat proses penyembuhan pasien selama pengobatan dan dapat dihentikan jika terdapat keraguan sebelum memberikan jenis dan dosis obat kepada pasien sesuai orderan dokter ${ }^{17}$.

\section{Prinsip Benar Waktu.}

Hasil penelitian ini menunjukkan sebagian besar perawat patuh dalam menerapkan seluruh item prinsip benar waktu dalam pemberian obat. Hasil observasi peneliti didapatkan sebagian besar perawat melakukan prinsip benar waktu sesuai dengan standar yang berlaku. Tindakan yang paling banyak tidak dilakukan yaitu perawat tidak meninggalkan obat yang belum diminum di kamar pasien. Saat penelitian dilakukan, masih ditemukan perawat meninggalkan obat-obat oral di kamar pasien dan tidak memastikan obat itu diminum oleh pasien. Hal tersebut dapat dikarenakan beban kerja perawat yang cukup tinggi mengingat banyaknya jumlah pasien yang ada dengan perawat jaga yang masih kurang sehingga perawat langsung meninggalkan kamar pasien tanpa memastikan obat diminum oleh pasien.

Hasil penelitian ini sejalan dengan penelitian Dewi (2017) yaitu penerapan prinsip benar waktu dengan kriteria $\mathrm{Ya}$ sebanyak 26 responden $(83,87 \%)^{12}$. Resiko kesalahan waktu pemberian obat akan menurun apabila perawat patuh dalam memberikan obat sesuai waktu yang ditetapkan ${ }^{12}$. Prinsip ini menjadi salah satu tolak ukur keberhasilan bagian 
prosedur pemberian terapi pengobatan pasien. Pemberian obat pada waktu yang tepat juga memiliki peran terhadap kesembuhan pasien sehingga obat yang diberikan sesuai dengan efek terapeutik yang diharapkan? ${ }^{7}$.

\section{Prinsip Benar Cara Pemberian.}

Hasil penelitian ini menunjukkan sebagian besar perawat patuh dalam menerapkan seluruh item dalam prinsip benar cara pemberian dalam pemberian obat. Berdasarkan hasil observasi didapatkan bahwa perawat melakukan prinsip benar cara pemberian obat sesuai dengan standar yang berlaku. Hasil penelitian Sthephani, Dewanto, Widijati (2015) menunjukkan hasil $100 \%$ responden sudah melakukan prinsip benar cara pemberian dan dokumentasi ${ }^{15}$. Sebagian besar perawat mencatat prosedur dan respon dan keluhan pasien setelah memberikan obat di catatan perkembangan dan hanya terdapat satu perawat yang tidak melakukan item tersebut.

Menurut Pranasari (2016) setelah perawat memberikan obat, perawat sering lupa melakukan pendokumentasian, dan langsung beralih pada tindakan lain ${ }^{3}$. Hal ini bisa mengakibatkan tidak ada bukti yang menunjukkan bahwa perawat telah melakukan tindakan pemberian obat sehingga berisiko terjadinya pemberian obat secara berulang. Hal ini berpengaruh terhadap kualitas pelayanan keperawatan, akibat tidak adanya bukti tindakan yang telah dilakukan perawat ${ }^{3}$. Menurut Dewi (2017) perawat belum menerapkan salah satu item dari prinsip benar dokumentasi tersebut dikarenakan adanya beban kerja yang tinggi, sehingga perawat tidak langsung melakukan pendokumentasian terhadap tindakan yang dilakukan ${ }^{12}$.

\section{SIMPULAN DAN SARAN}

Hasil penelitian yang dilakukan menunjukkan dalam penerapan prinsip lima benar pemberian obat berdasarkan SPO di satu rumah sakit swasta di Indonesia tengah masih kurang yaitu $70,59 \%$ perawat masih tidak patuh. Perawat diharapkan dapat mengevaluasi dan meningkatkan kesadaran pentingnya penerapan prinsip benar pemberian obat. Pimpinan keperawatan harus dapat mengevalusi dan mendorong perawat, serta memberikan pelatihan dalam penerapan prinsip benar pemberian obat. Rumah sakit diharapkan dapat meningkatkan kualitas pelayanan khususnya keperawatan dalam menjaga keselamatan pasien.

\section{DAFTAR PUSTAKA}

1. Natasia N, Loekqijana, Janik K. Faktor yang mempengaruhi kepatuhan pelaksanaan SOP asuhan keperawatan di ICU-ICCU RSUD Gambiran Kota Kediri. Jurnal Kedokteran Brawijaya. 2014;28.

2. Potter PA, Perry AG. Fundamental of nursing. Edisi 7 Buku 2. Jakarta: Salemba Medika; 2009.

3. Pranasari R. Gambaran Pemberian obat dengan prinsip 7 benar oleh perawat di RSU PKU Muhammadiyah Bantul. 2016. Available from http://repository.umy.ac.id/bitstream/ha ndle/123456789/2697/NASKAH\%20P UBLIKASI.pdf?sequence $=11$ \&isAllowe $\mathrm{d}=\mathrm{y}$.

4. Mahajan RP. Medication error. European Society of Anaesthesiology. University of Nottingham. United Kingdom; 2011

5. Anwar, Kontoko RR, Wardiyah D, Yuswardi. Hubungan fungsi manajemen kepala ruang dengan penerapan "Patient Safety Culture" di Rumah Sakit Umum Dr. Zainoel Abidin Banda Aceh. Jurnal Keperawatan Unsyiah, VII. 2016. Available from http://www.jurnal.unsyiah.ac.id/INJ/ article/download/6465/ 5302

6. Fatimah FS. Gambaran penerapan prinsip benar pemberian obat di Rumah Sakit PKU Muhammadiyah Yogyakarta Unit II. JNKI:4(2), 2016, 79-83. Available from https://ejournal.almaata.ac.id/index.ph p/JNKI/article/download/245/237.

7. Mahfudhah, Mayasari. Pemberian obat oleh perawat di ruang rawat inap 
Rumah Sakit Umum Kota Banda Aceh. JIM FKEP:III(4), 2018.

8. Gorgich EAC, Barfroshan S, Ghoreishi G, Yaghoobi M. (2015). Investigating the causes of medication errors and strategies to prevention of them from nurses and nursing student viewpoint. Glob J. Health Sci. Iran, 2015

9. Hosseinzadeh $M$, Aghajari EP, Mahdavi N. Reasons of nurse's medication errors and perspectives of nurses on barriers of error reporting. Hayat, 2012

10. Indarti E, Aulawi K, Kristanti MS. Kejadian nursing error pada pemberian obat di ruang rawat inap salah satu rumah dakit di Sulawesi Tengah. JIK Vol. 04 No. 3, 2009.

11. Solagracia. Gambaran pemberian obat di Instalasi Gawat Darurat RSUD K.R.M.T Wongsonegoro Semarang. 2017. Available from http://eprints.undip.ac.id/54758/1/glory 22020112130065.pdf

12. Dewi All. Gambaran tindakan pemberian obat yang benar pada pasien rawat inap di RSU Bahteramas Provinsi Sulawesi Tenggara. [Skripsi]. Kendari: Politehnik Kesehatan; 2017. Available from http://repository.poltekkes-

kdi.ac.id/view/creators/Agung_Ayu_Ind rasari_Dewi $=3 \mathrm{APenulis}=3 \mathrm{~A}=3 \mathrm{~A}$. default .html

13. Kozier BEG. Fundamental keperawatan, konsep proses dan praktik. Jakarta: EGC; 2010

14. Eljardali. Predictors and outcomes of patient safety culture in hospital. BMC Health Services Research 11(45). 2011. Available from http://www.biomedcentral.com/1472 6963/11/45

15. Sthephani $\mathrm{P}$, Dewanto $\mathrm{A}$, Widijati $\mathrm{Cl}$ Faktor penghambat pelaksanaan SPO 7 benar dalam pemberian obat di ruang rawat inap Rumah Sakit Panti Nirmala. Jurnal Kedokteran Brawijaya 28(2); 2015.

16. Tirtawati NK. Evaluasi terhadap penerapan sistem pelayanan UDD (Unit Dose Dispensing) di Rumah Sakit Umum Dr. M. M. Dunda.
Universitas Negeri Gorontalo. 2014. Available from http://eprints.ung.ac.id/4904/

17. Boyer MJ. Perhitungan dosis obat: Panduan praktis untuk menghitung dosis dan menyiapkan obat. Edisi 7 Surabaya: Erlangga; 2013. 